\title{
ECTOPIC OVEREXPRESSION OF BARLEY PIP2;4 CONFERS SALT TOLERANCE IN ARABIDOPSIS
}

\author{
Jayeeta Mitra, Jay Prakash Awasthi and Sanjib Kumar Panda* \\ Plant Molecular Biotechnology Laboratory, Department of Life Science and Bioinformatics, Assam University, Silchar-788011, Assam, India \\ *Corresponding author, email address: drskpanda@gmail.com
}

\begin{abstract}
In the present study HvPIP2; 4 was overexpressed in Arabidopsis thaliana to engineer enhanced salt tolerance. Barley Aquaporin was selected since barley shows fairly good tolerance to drought, salt stress and low temperature compared to many other crops including rice, and it was thought that analysis of barley aquaporin will provide a good insight into the molecular mechanisms involved in transport of water \& their efficacy during abiotic stress condition. Arabidopsis line expressing $H v P I P 2 ; 4$ from annual crop plant Hordeum vulgare (Barley) under the control of constitutive promoter was used to analyze the expression of $H v P I P 2$; 4 and its efficacy during salt stress when $\mathrm{NaCl}$ concentration gradually increased. The pattern of expression of $\mathrm{H \nu PIP2} ; 4$ were found to be $\mathrm{NaCl}$ dose dependent during salt stress. The constitutive expression of $H v P I P 2 ; 4$ enhanced salt stress tolerance in Arabidopsis. HvPIP2;4 played a dominant role in improving plant salt tolerance. It may be very well presumed that overexpression of $H v P I P 2 ; 4$ in crop plant might benefit them by enhancing their salt tolerance capacity.
\end{abstract}

Keywords: Aquaporin; PIP2;4; Overexpression; Barley; Arabidopsis

\section{Introduction}

Water plays a very important role in plant growth and development, a fundamental requirement of the proper growth of plants is adequate uptake of water and its flow across the membrane (Agre and Homer, 2000). Vital processes such as cellular respiration and photosynthesis requires the presence of water (Taiz and Zeiger, 2006). Water transport within and between plants tissues uses both the apoplastic and the symplastic routes; therefore, a fairly large number of cellular membranes are to be crossed by the water molecules (Quigley et al., 2002). Aquaporins, a family of water channel proteins controls and maintains the radial component of symplastic route (Amodeo et al., 1999).Water gets transported across the membrane either through diffusion via the lipid bilayer and/or through the water channel proteins aquaporins (Preston et al., 1992). Peter Agre and his team first discovered the phenomenon of water transport facility via aquaporins in John Hopkins University in early 1990s. The aquaporins facilitate in the rapid and regulated movement of water across the membrane. The presence of aquaporins has been found in bacteria, fungi, animals and plants. Due to their universal presence they are supposed to play an important part in life cycle (Heymann and Engel, 1999). Plant aquaporin was first discovered by Maurel et al., 1993 thereafter a large number of plant aquaporin has also been reported from other plant species such as Arabidopsis 35, Tomato 47, Maize 36, Rice 33 and 71 in Cotton (Johanson et al., 2001; Chaumont et al., 2011; Sakurai et al., 2005; Park et al., 2010). Some selective aquaporins increases 10-20 times the hydraulic conductivity of the membrane. In various studies it was found that a rise in concentrations of salt has shown to inhibit root water uptake due to reduction in root hydraulic conductance and thereby increasing the transmembrane diffusion efficiency of water (Obroucheva et al., 2010). Several measures such as heterologous co expression in oocytes, interaction of proteins and their detection in mutant yeast, overexpression of certain genes in plants and inhibitors have been utilized to analyze the functionality of aquaporins. Among abiotic stressors salt stress plays a major role for the reduction of crop yield worldwide (Kronzucker and Britto, 2011). Salinity had affected about half of the world's irrigated land and more than $20 \%$ of the cultivated land (Mahajan and Tuteja, 2005).To cope with the increasing food requirement minimization of losses incurred due to abiotic stress is a major concern for all 
nations. To mitigate stress ion homeostasis and water needs to be regulated so that water deficit and/or ion toxicity can be avoided. With the discovery of plant aquaporin it was thought that they play an integral role in adaptation of salinity and drought stress by metabolically controlling the flow of water (Maurel et al., 2002, Baiges et al., 2002). Barley (Hordeum vulgare L.) is diploid, contains 14 chromosomes, is self-pollinating and it belongs to the grass family. Barley is fairly good salt and drought tolerant plant, many barley varieties have been evaluated from the stand point of salt tolerance. Several PIP genes have been identified in Barley $H v$ PIP1; 3, $H v$ PIP1; 6 and $H v$ PIP2; 1 have already been characterized and their functionality as water channels have been verified in Xenopus laevis oocytes (Hollenbach and Dietz, 1995; Katsuhara et al., 2002; Katsuhara and Shibasaka 2007; Wei et al., 2007). Expressed Sequence tag (EST) were analyzed for barley and it was found that a large number of $P I P 1$ and $P I P 2$ gene exist in barley similarly as found in other plant species (Katsuhara et al., 2008). These findings lead us in studying and characterizing new $H v P I P$ s so that we can have a clear idea about the water transport mechanism controlled by $H v P I P$ aquaporin in barley plants. It is believed that functional characterization will give new insights regarding the role of $H v P I P 2 ; 4$ gene. In the current study an independent transgenic Arabidopsis line carrying $H v P I P 2 ; 4$ under the control of constitutive promoter was obtained, and the expression patterns of $H v P I P 2 ; 4$ in transgenic Arabidopsis exposed to salinity was analyzed.

\section{Materials and Methods}

\section{Plant Materials and Treatment Conditions}

Barley (Hordeum vulgare cv. NP21) seeds were procured from Indian Agricultural Research Institute, Pusa, New Delhi and germinated in dark for 3 days on two layers of moist filter paper disk placed on a Petri dish at $30 \pm 1{ }^{\circ} \mathrm{C}$. After 3 days, the germinated seeds were transferred to Hoagland's nutrient medium $(\mathrm{pH}$ 6.2) and grown hydroponically. The seedlings were grown in a growth chamber under continuous white light provided with cool, fluorescent white tubes, for 7 days. Arabidopsis thaliana, ecotype Columbia (Col-0) was kept at $22^{\circ} \mathrm{C}$ in a soil-peat mixture for $10 \mathrm{~h}$ under light and watered twice a week with tap water.

\section{Isolation of HvPIP2; 4 Target Gene}

Total RNA isolation was done as described by (Bilgin et al., 2009). One microgram of total RNA was reverse transcribed to cDNA by using the cDNA Synthesis Kit (Thermo Fischer Scientific, Waltham, MA, USA) followed by cloning in pTZR/T(Thermo Fisher Scientific, Waltham, MA, USA) and sequenced. It was found to show $100 \%$ homology with $H v P I P 2 ; 4$ gene reported by Panda et al (2005).

\section{Binary Vector Preparation and Transformation in to the Model Plant}

HvPIP2; 4 was sub cloned into a constitutive Cauliflower Mosaic Virus (CaMV) 35S promoter/CaMV strain Cabb B$\mathrm{D}$ polyadenylation signal cassette, within the intermediate vector pRT101 (Töpfer et al., 1987). Using the restriction site HindIII, the CaMV35S promoter-HvPIP2;4-35S terminator cassette was subsequently transferred to T-DNA portion of plant binary vector pCAMBIA $2301(11.6 \mathrm{~kb})$. Neomycin phospho-transferase gene (nptII) selectable marker for plant transformation and b-glucuronidase gene (gus) from E. coli beta-glucuronidase gene, it is a gene fusion marker and used for gene expression analysis are present in the T-DNA region of pCAMBIA2301 and are regulated by cauliflower mosaic virus (CaMV) $35 \mathrm{~S}$ promoter (Fig.1). The resulting recombinant plant binary vector was labeled as pCAMBIA2301-35S::HvPIP2;4 $(13.1 \mathrm{~kb})$, and electroporation at $1250 \mathrm{~V}$ with capacitance of $25 \mathrm{mF}$ and resistance of $400 \mathrm{ohm}$ was used to transfer the recombinant plant binary vector pCAMBIA 230135S::HvPIP2;4 into A.tumifaciens GV3101 strain (Sambrook and Green 2001, Nagel et al., 1990). Arabidopsis thaliana (ecotype Columbia) was transformed inplanta via floral dipping method with the construct (Clough and Bent, 1998). The $\mathrm{T}_{1}$ transgenic lines were screened on 1/2 MS Medium (from Duchefa, Haarlem, Netherlands) supplemented with $50 \mathrm{mg} / \mathrm{l}$ Kanamycin (Duchefa, Haarlem, Netherlands). The selection of transgenic was continued until $\mathrm{T}_{3}$ generations to bearing transgenic homozygote lines that have a single T-DNA locus (35S::HvPIP2; 4).

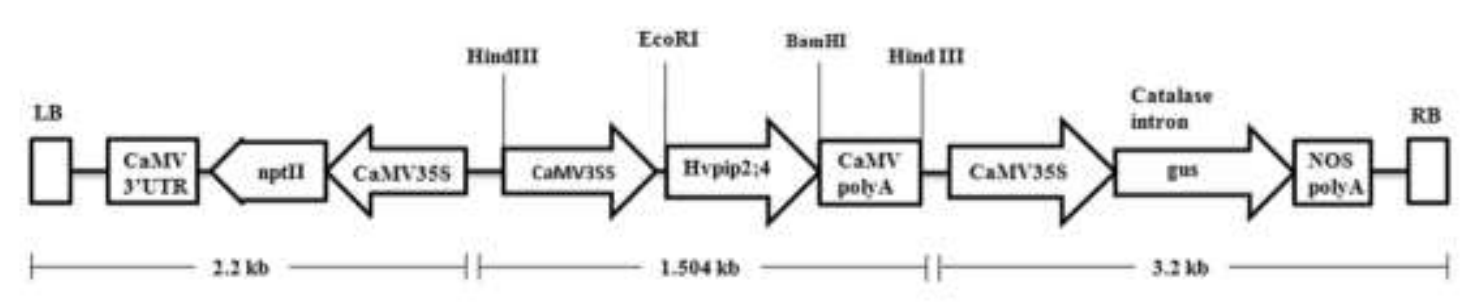

Fig. 1: T DNA Region of pCAMBIA $2301 H v P I P 2 ; 4$ (1.504bp).The 873 bp fragment containing $H v$ PIP

2;4 under control of CaMV35S promoter and NOS terminator.LB and RB: left border and right border of T-DNA region, NOS T :nos terminator, 35P:CaMV35S promoter, nptII: neomycinphosphotransferase-II. 


\section{Screening of the Putative Transformed Plants}

For screening of the putative transformed plants Genomic DNA was isolated from $\mathrm{T}_{3}$ transformed putative $H \nu \mathrm{PIP} 2 ; 4$ overexpressing lines and non- transformed plants using CTAB method (Rogers and Bendich, 1988). The presence of $n p t I I$ was detected by polymerase chain reaction (PCR) in $\mathrm{T}_{3}$ transformed putative plants. Primers (forward primer 5'-CCACCATGATATTCGGCAAC-3' and reverse primer 5'-GTGGAGAGGCTATTCGGCTA-3') amplified 0.54-kb fragment of nptII. PCR condition was $94^{\circ} \mathrm{C}$ for $5 \mathrm{~min}$; 1 cycle, $94^{\circ} \mathrm{C}, 1 \mathrm{~min}, 58^{\circ} \mathrm{C}, 1 \mathrm{~min}, 72^{\circ} \mathrm{C}, 1 \mathrm{~min} ; 35$ cycles, $72^{\circ} \mathrm{C}, 7 \mathrm{~min}$; 1cycle. PCR fragments were analyzed on $1 \%$ agarose gel and stained with $10 \mathrm{mg} / \mathrm{ml}$ ethidium bromide.

\section{Phenotypic Changes under Salt Stress}

The 4 days old germinating seedlings were transferred to $1 / 2 \mathrm{MS}$ media liquid and plants were grown at $23^{\circ} \mathrm{C}$. The photoperiod lasted for 16 hour with 8 hours in dark, under fluorescent illumination supplemented by incandescent light yielding an intensity of $100-150 \mathrm{mE} / \mathrm{m} 2 \times$ s. Salt stress of $(0 \mathrm{mM}, 100 \mathrm{mM}$ and $200 \mathrm{mM})$ was imposed hydroponically for $48 \mathrm{hrs}$ and phenotypic changes were recorded.

\section{Measurement of Growth Parameters under Salt Stress}

Determination of Plant root growth. The 4 days old germinated seedlings were transferred to $1 / 2 \mathrm{MS}$ Medium liquid supplemented with $(0 \mathrm{mM}, 100 \mathrm{mM}$ and $200 \mathrm{mM})$ $\mathrm{NaCl}$ for 1 week and the difference in root length of the wild type WT and $\mathrm{T}_{3}$ independent transgenic line of Arabidopsis seedlings expressing $H v P I P 2 ; 4$ was measured by using ImageJ software (Schneider et al., 2012). Mean data was collected from at least three independent experiments for wild type and $\mathrm{T}_{3}$ Kanamycin selected transgenic Arabidopsis line.

\section{Determination of Chlorophyll Content}

The 10 day old germinated seedlings were transferred to $1 / 2$ MS liquid supplemented with (0mM, 100mM, and 200mM) $\mathrm{NaCl}$ for 5 days. In order to measure the chlorophyll content, $150 \mathrm{mg}$ of shoot tissue was grounded with liquid nitrogen and the powder was transferred into centrifuge tube. $2.5 \mathrm{ml}$ of $80 \%$ acetone was added into the tube and mixed well and placed in dark for 15- $30 \mathrm{~min}$. After centrifugation at $4^{0} \mathrm{C}$ for $15 \mathrm{~min}(3,000 \mathrm{rpm})$ the supernatant was transferred to a new centrifuge tube and the absorbance was read spectrophotometrically (Bacman coulter DU 730 UV- Vis Spectrophotometer) at $663 \mathrm{~nm}$ and $645 \mathrm{~nm}$ (Arnon, 1949).

\section{Determination of Dry and Fresh Biomass}

To determine fresh biomass the wild type and transgenic samples were weighed after sampling, for the dry biomass, samples were dried in oven at $65^{\circ} \mathrm{C}$ for $48 \mathrm{~h}$ and then weighed to determine the dry biomass.

\section{Relative Water Content (RWC) Analysis}

Leaf segment were excised from fully expanded leaves and fresh weight $(\mathrm{FW})$ was recorded. The segments were then allowed to float on deionized water for about 4hours and turgid weight (TW) was recorded. The leaf segments were dried at $80^{\circ} \mathrm{C}$ for 24 hours dry weight (DW) recorded and RWC calculated.

\section{Results}

\section{Molecular Analyses of Transgenic Plants}

The presence of the expected 540bp amplified product corresponding to $n p t I I$ in kanamycin-resistant $\mathrm{T}_{3}$ transgenic plant was detected by PCR analysis. Amplification was not found in the control untransformed plant (Fig 2).

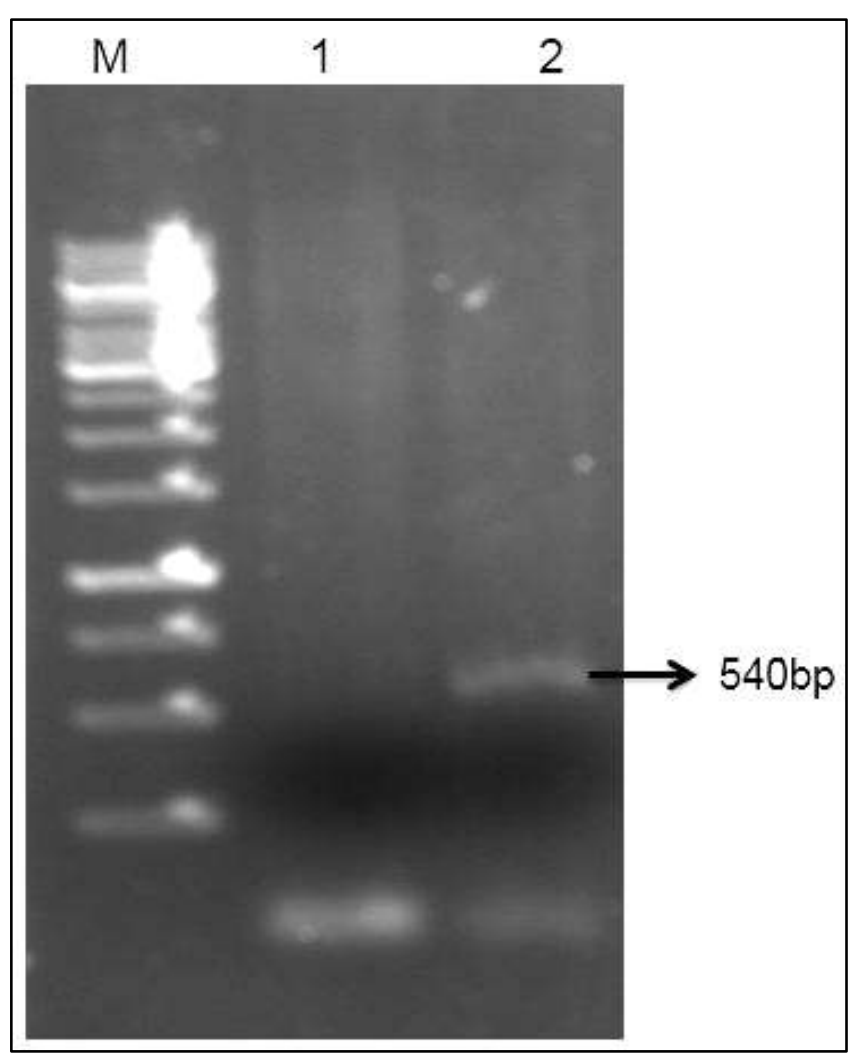

Fig. 2: Molecular analysis of T3 transformed plants. PCR amplification of the 540bp fragment of the nptIIgene.Lane $\mathrm{M} 1 \mathrm{~Kb}$ Marker, lane 1 DNA from untransformed plants (negative control), lane 2 DNA from independently transformed plants.

\section{Growth of Transgenic Arabidopsis Overexpressing HvPIP2;4 under Salt Stress}

To validate the function of $H v P I P 2 ; 4$ on model plant Arabidopsis during salt stress, independent $\mathrm{T}_{3}$ homozygous Arabidopsis line expressing HvPIP 2;4 through constitutive CaMV35S promoter were subjected to salt stress. The differences in their growth and survival were monitored and scored (Fig. 3).

\section{Phenotypic Observation}

Phenotypic observation clearly showed the transgenic ecotypes were more tolerant than wild type. Growth of the 
plant stunted with time and increasing $\mathrm{NaCl}$ concentration (0mM, 100mM, and $200 \mathrm{mM})$ in both wild type and transgenic plants. After $48 \mathrm{hrs}$ with the increase in the concentration of $\mathrm{NaCl}$ both wild type and transgenic ecotypes were affected but the transgenic ecotypes showed more resilience (Fig. 4).

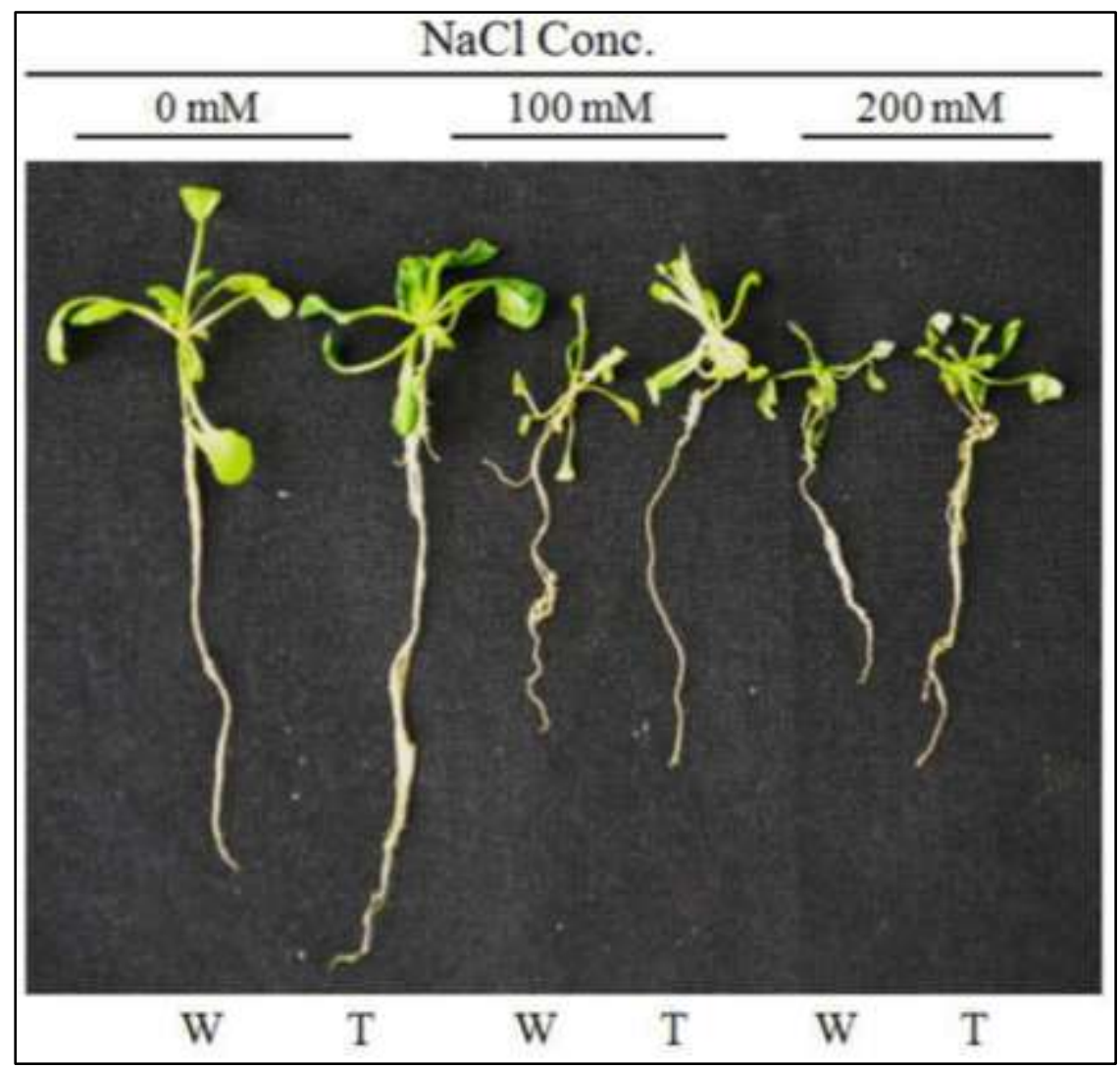

Fig. 3: Studying the physiological changes in transgenic Arabidopsis line under salt stress. Effect of Salt stress on wild type (WT Col-0) and transgenic Arabidopsis line expressing $\mathrm{HvPIP2} ; 4$ constitutively. $\mathrm{NaCl}$ induced morphological changes was visible in 10 days old WT and transgenic lines after exposure to (0mM, $100 \mathrm{mM}, 200 \mathrm{mM}) \mathrm{NaCl}$ for $48 \mathrm{~h}$.

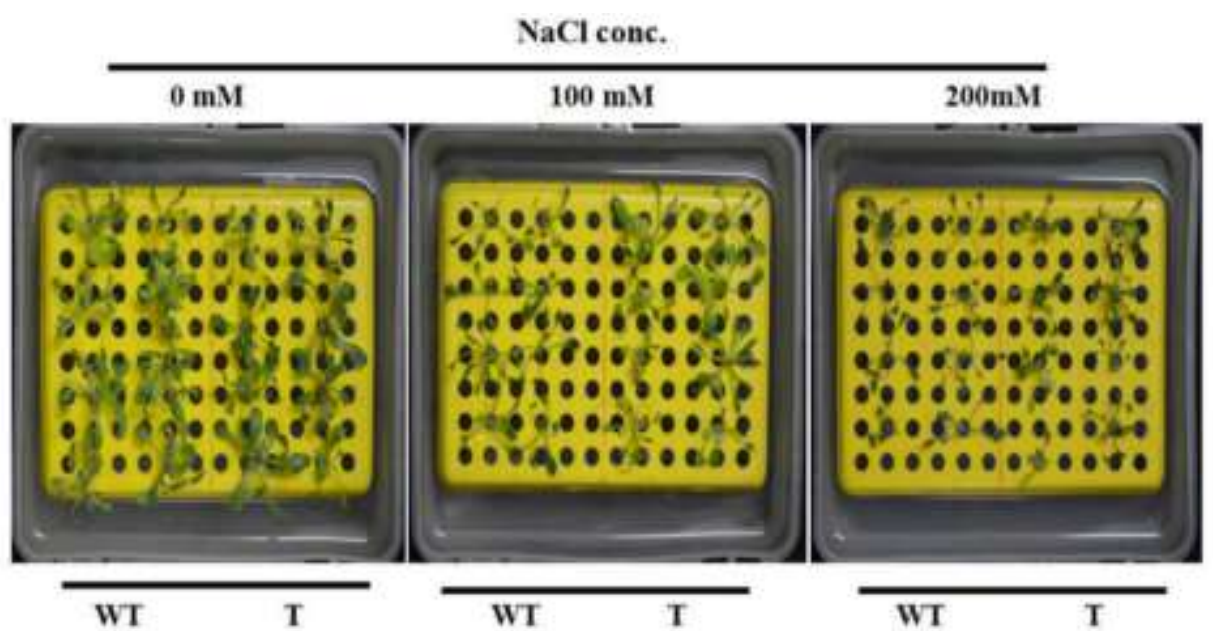

Fig. 4: Studying the physiological changes in transgenic Arabidopsis line under salt stress. Effect of Salt stress on wild type (WT Col-0) and transgenic Arabidopsis lines expressing $\mathrm{HvPIP2} ; 4$ constitutively. $\mathrm{NaCl}$ induced morphological changes was visible in 15 days old WT and transgenic line after exposure to (0mM, 100mM, 200mM) NaCl for $48 \mathrm{~h}$. 


\section{Estimation of Fresh Weight and Dry Weight}

The transformed ecotypes showed an increase in dry weight and fresh weight compared to wild types. With the onset of stress $(100 \mathrm{mM} \& 200 \mathrm{mM})$ a decrease in the fresh weight and dry weight was observed in both the wild type and transgenic ecotypes. However the decrease in both fresh weight and dry weight was found to be more in wild types than in transgenic ones (Fig 5 \& Fig. 6).

\section{Physiological Growth Parameters}

The Physiological growth parameter (root length was scored in WT and independent $\mathrm{T}_{3}$ homozygous transgenic Arabidopsis line expressing HvPIP2;4 constitutively $(35 \mathrm{~S}:: H v P I P 2 ; 4)$. It was subjected to $(0 \mathrm{mM}, 100 \mathrm{mM}$, $200 \mathrm{mM}) \mathrm{NaCl}$ conc. After 7 days of salt stress the difference in root length was measured. Under control unstressed condition also a significant difference in the root length was found between WT and transgenic Arabidopsis line expressing $H v P I P 2 ; 4$ constitutively. Inhibition of root growth were clearly observed with the increase in $\mathrm{NaCl}$ concentration $(0 \mathrm{mM}, 100 \mathrm{mM} \& 200 \mathrm{mM} \mathrm{NaCl})$ in WT and $\mathrm{T}_{3}$ transgenic line, there was inhibition in the root growth rate of both WT and transgenic line under salt stress $(100 \mathrm{mM}$ and $200 \mathrm{mM}) \mathrm{NaCl}$ With increase in $\mathrm{NaCl}$ concentration the root growth of both wild type and transgenic plants were affected but in comparison to wild type transgenic ecotypes had higher root length than the wild type hence they were able to survive (Fig. 7).

\section{Relative Water Content}

The relative water content is an indicator for water status in leaves. Under unstressed condition no significant difference was observed in the relative water content of wild type and transgenic ecotype with transgenic ecotype showing a slight increase in water content than the wild types. With the onset of stress $(100 \mathrm{mM}$ and $200 \mathrm{mM}) \mathrm{NaCl}$ there was a decrease in the plant water content of both wild type and transgenic ecotypes. The transgenic ecotype showed a less decrease in the water content than in wild type (Fig. 8).

\section{Physiological Studies}

Estimation of chlorophyll content. All the chlorophyll pigments showed higher presence in transgenic ecotypes right from the unstressed condition to gradual increase in stress $(100 \mathrm{mMNaCl}$ and $200 \mathrm{mMNaCl})$. With the onset of stressed conditions there was a decrease in amount of pigments but the transgenic ecotypes still retained higher amount of chlorophyll pigments than the wild ones (Fig. 9, $10,11 \& 12)$.

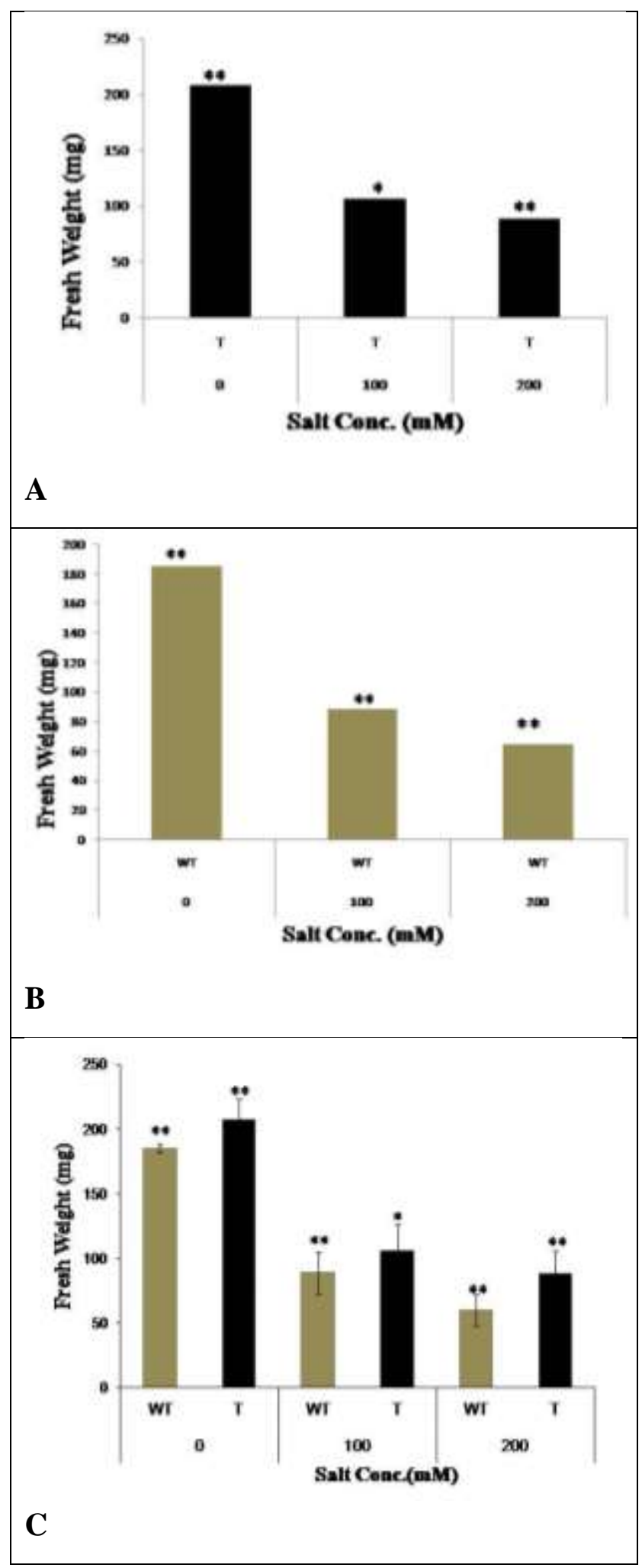

Fig.5: Changes in Fresh weight of the transgenic Arabidopsis line (A.), wild type (B.) and changes between Wild type line and Transgenic (C.) under different concentrations of Salt stress in hydroponic medium.

[The values are represented as the means $\pm \operatorname{SE}(n=3)$ of at least three independent experiments, where $n$ is the no of times experiment repeated and SE denotes Standard Error. Statistically significant values at $\mathrm{P} \leq 0.05$ and $\mathrm{P} \leq 0.01$ using Tukey analysis are indicated by '*' and '**' respectively.] 


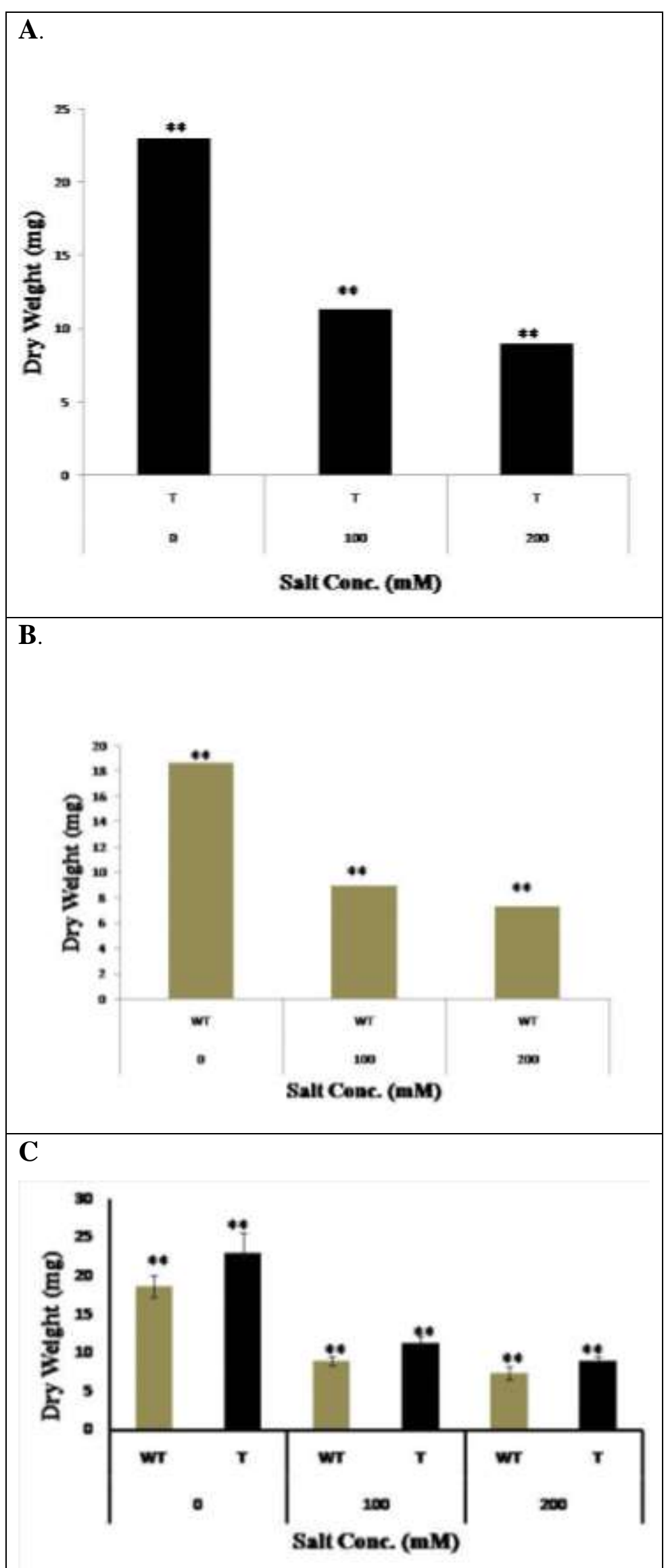

Fig. 6: Changes in dry weight of the transgenic Arabidopsis line (A.), the wild type (B.) and the changes between Wild Type and Transgenic Arabidopsis line (C.) under different concentrations of Salt stress in hydroponic medium.

[The values are represented as the means $\pm \mathrm{SE}(\mathrm{n}=3)$ of at least three independent experiments, where $\mathrm{n}$ is the no of times experiment repeated and SE denotes Standard Error. Statistically significant values at $\mathrm{P} \leq 0.05$ and $\mathrm{P} \leq 0.01$ using Tukey analysis are indicated by '*' and '**' respectively.] 


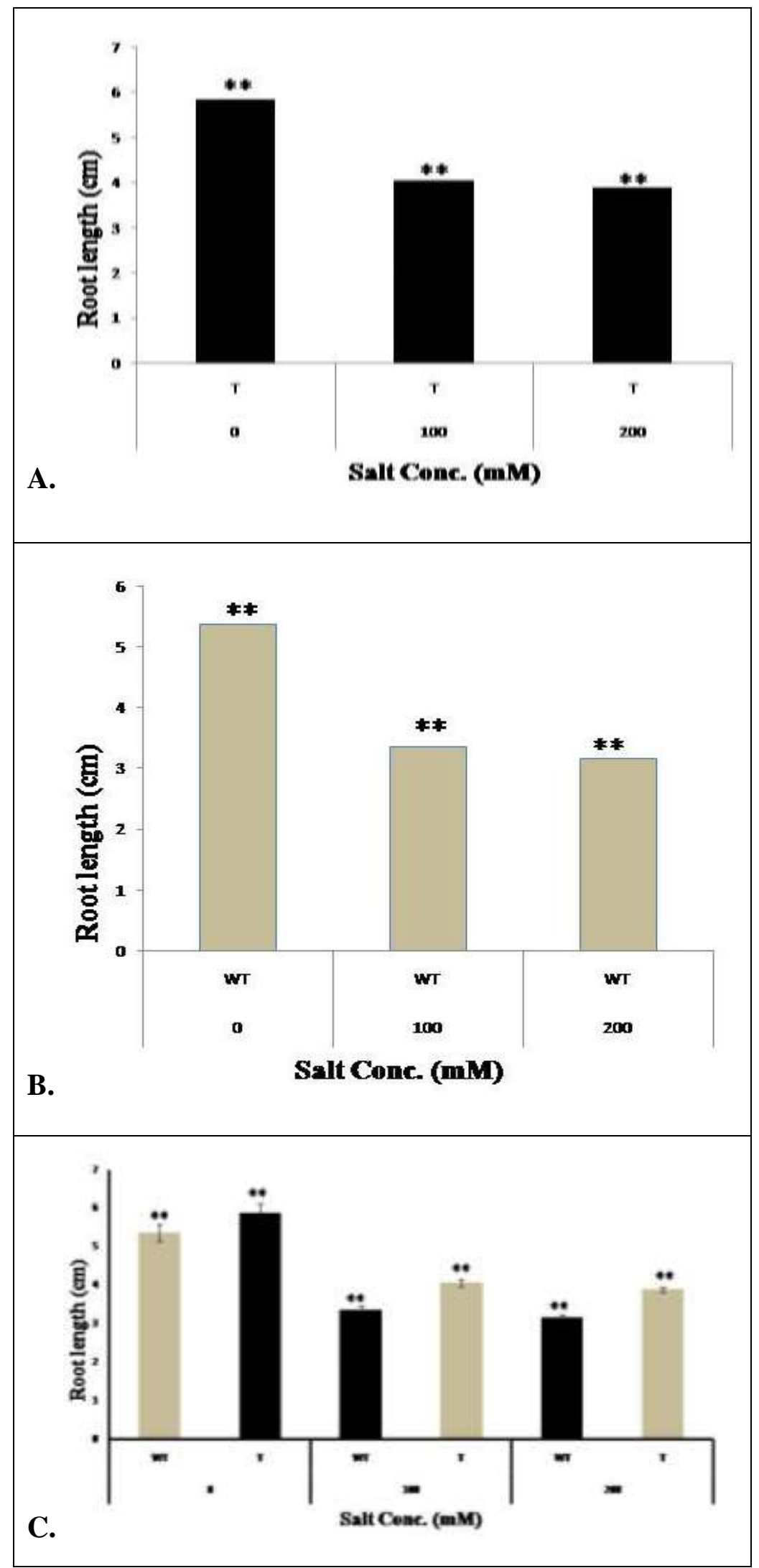

Fig. 7: Effect of salt stress on root growth of transgenic Arabidopsis line. Root growth inhibition in transgenic Arabidopsis plant (35S:: HvPIP2;4) (A.) and wild type (WT Col-0) (B.) upon salt stress (0mM.100mM,200mM) was studied. The 4 day old germinating seedlings was transferred to $(0 \mathrm{mM}, 100 \mathrm{mM}$ and $200 \mathrm{mM}) \mathrm{NaCl}$ stress and root length measured was plotted in a graph. (C.) Changes between Wild Type and Transgenic line 


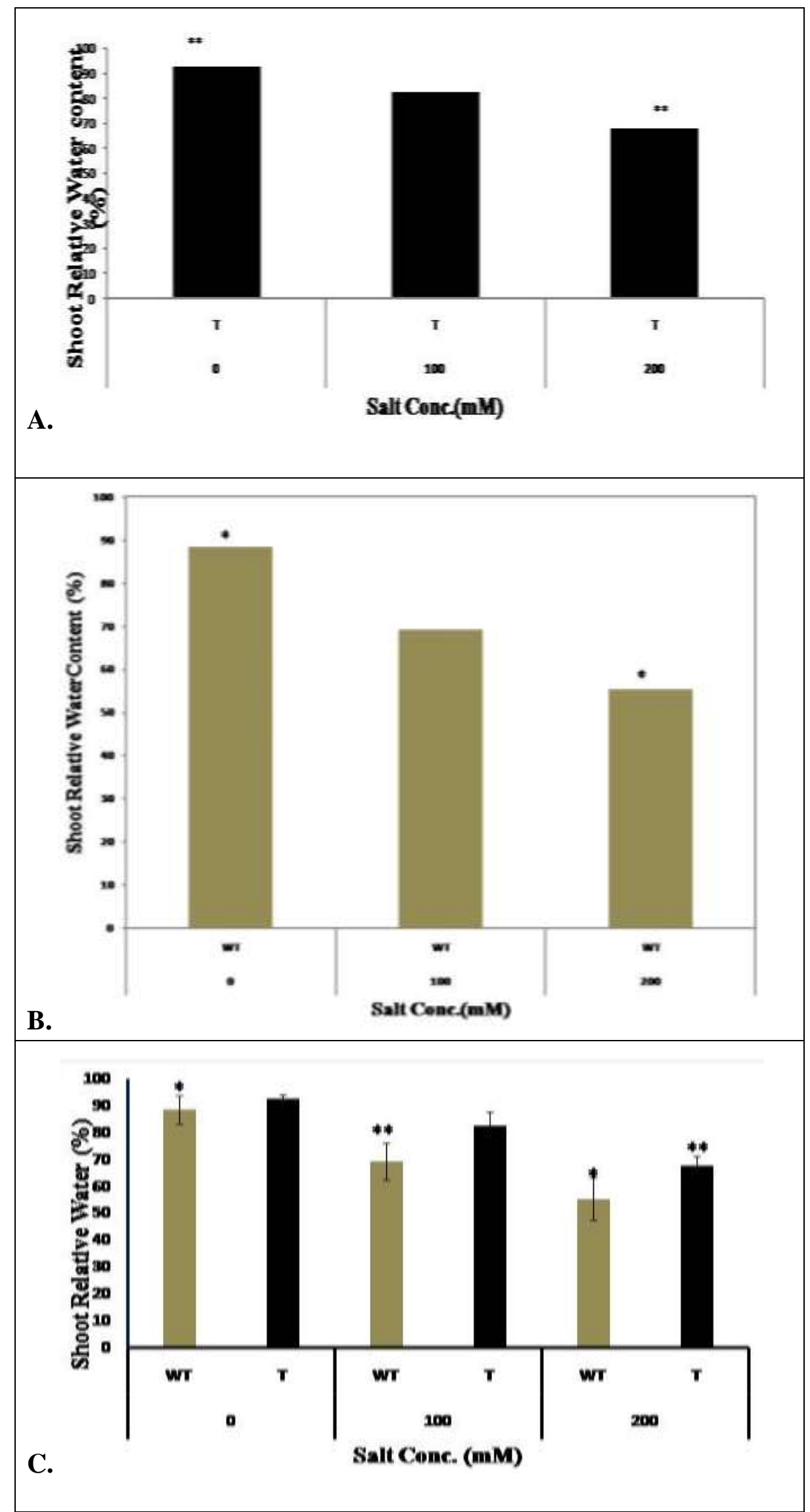

Fig. 8: Changes in Relative water content (\%) of the transgenic Arabidopsis line (A.) wild type (B.) and between Transgenic and Wild type (C.) under different concentrations of Salt stress in hydroponic medium. 


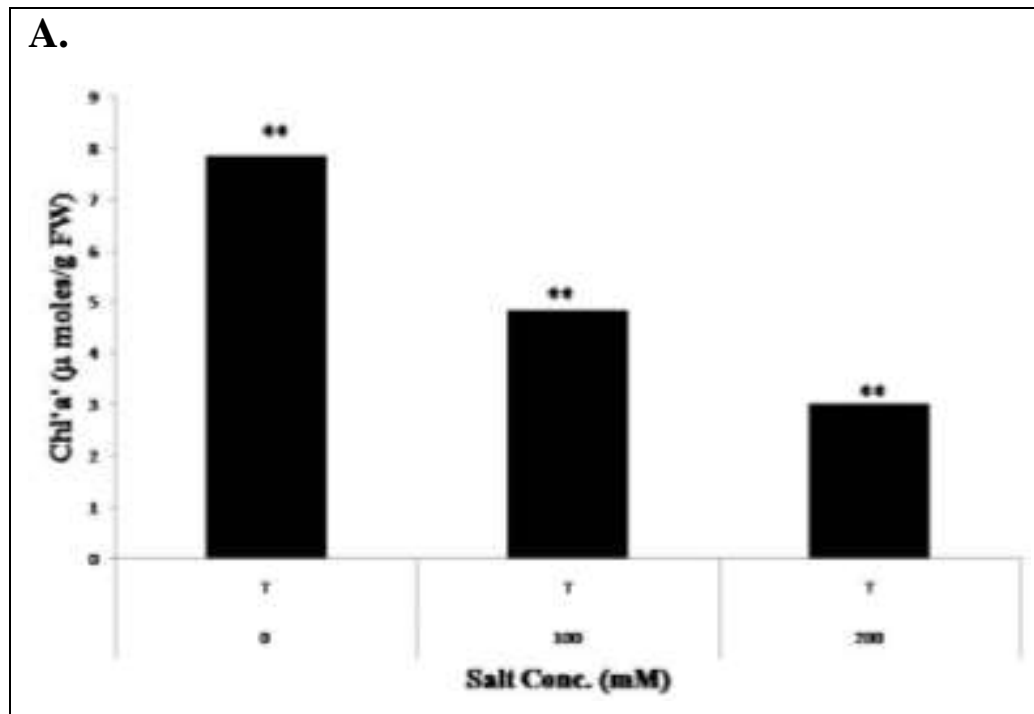

B.

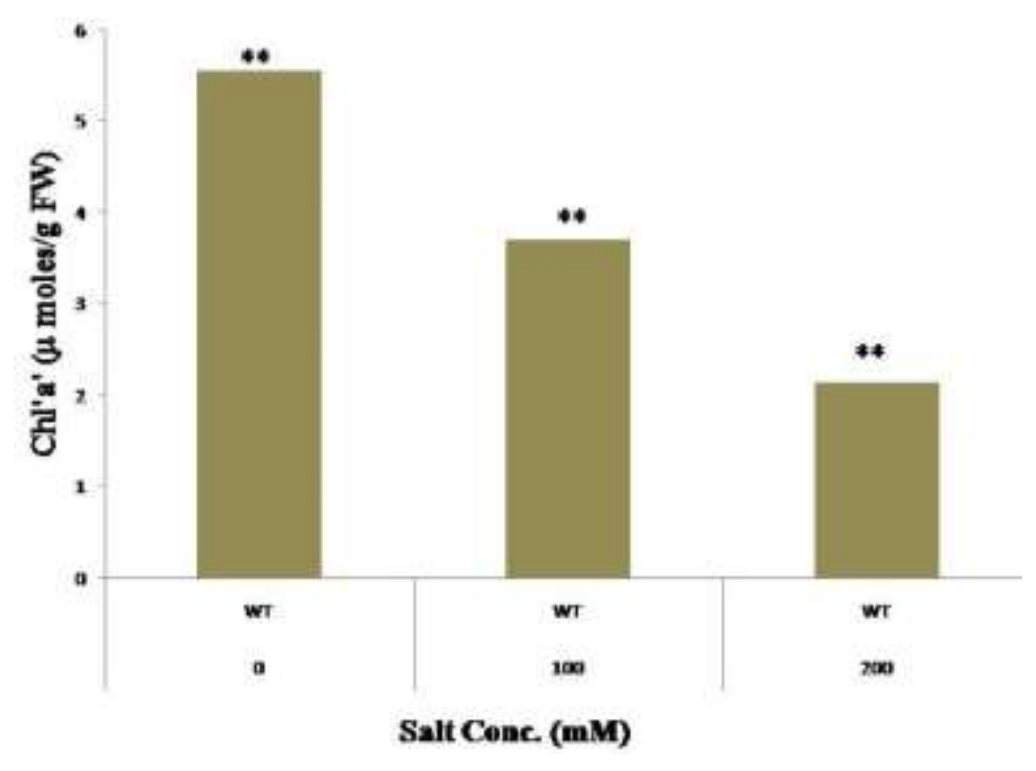

C.

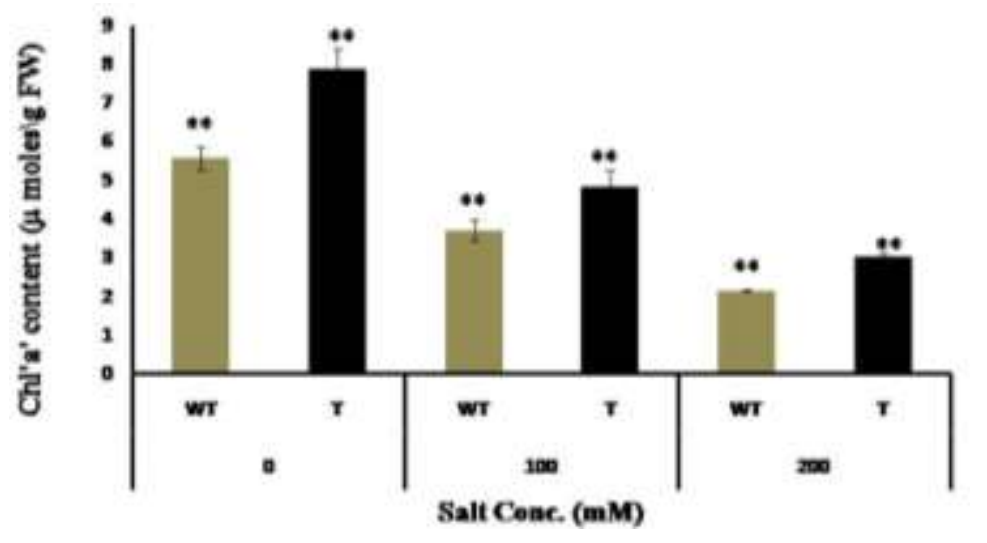

Fig. 9: Effect of Salt stress on Chlorophyll-a of transgenic Arabidopsis (A.), Wild type (B.) and between Wild type and transgenic Arabidopsis (C.) 


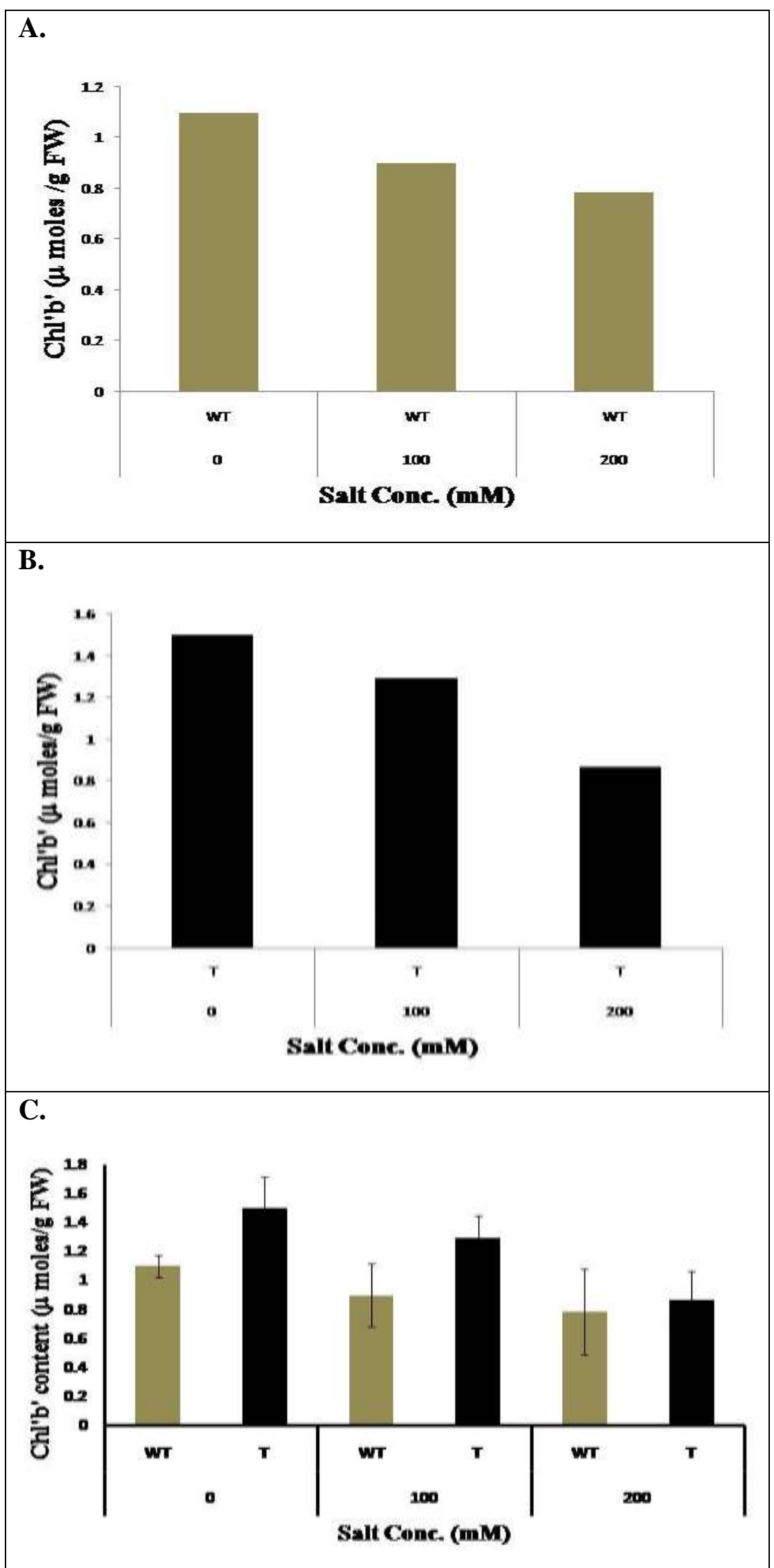

Fig. 10: Effect of Salt stress on chlorophyll-b, Wild type (A.), transgenic Arabidopsis (B.) and in between Wild type and Transgenic plants (C.). 


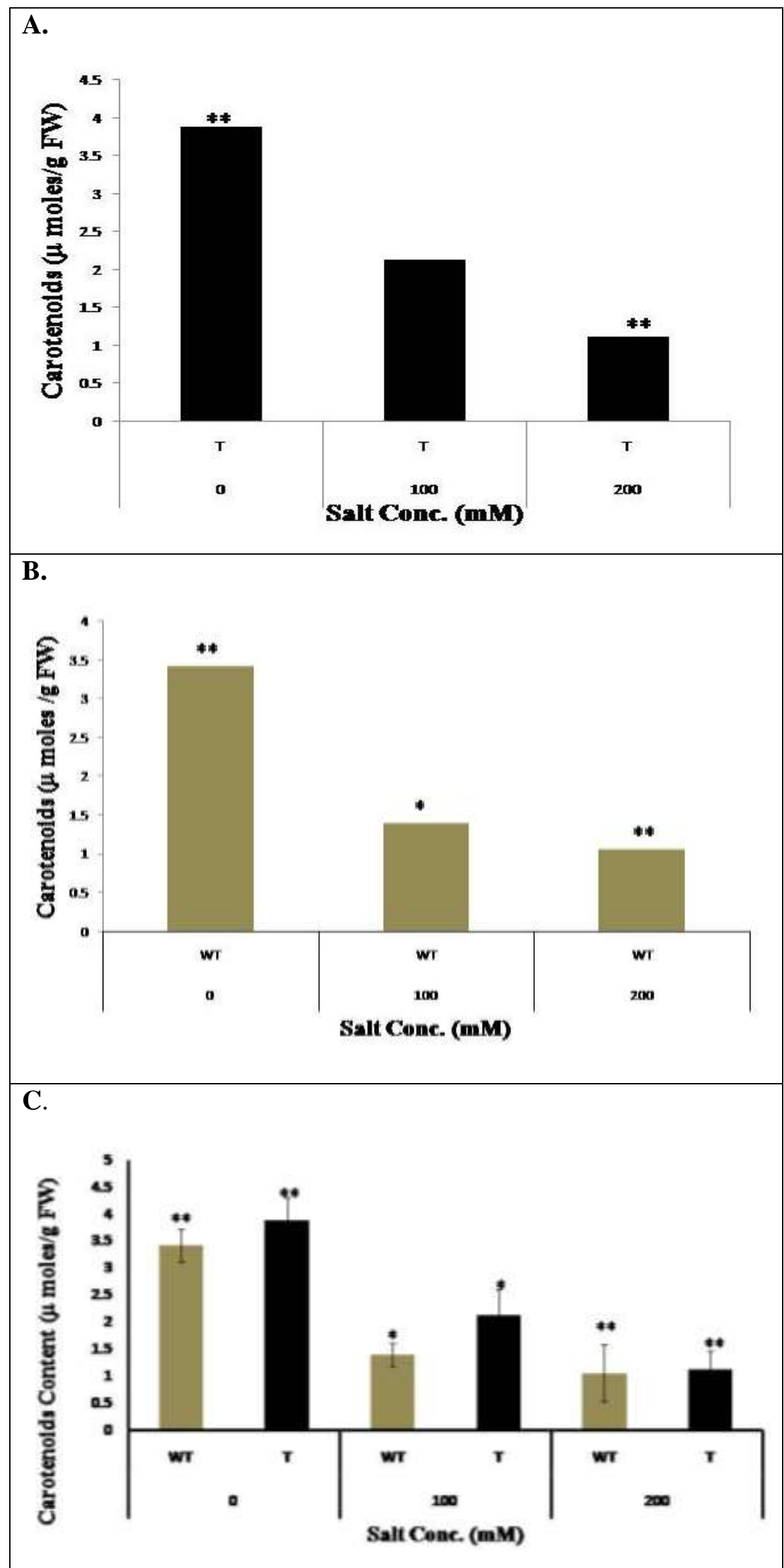

Fig. 11: Effect of Salt stress on Carotenoid content of transgenic plant (A.), Wild type (B.) and between Wild type and transgenic Arabidopsis line (C.). 


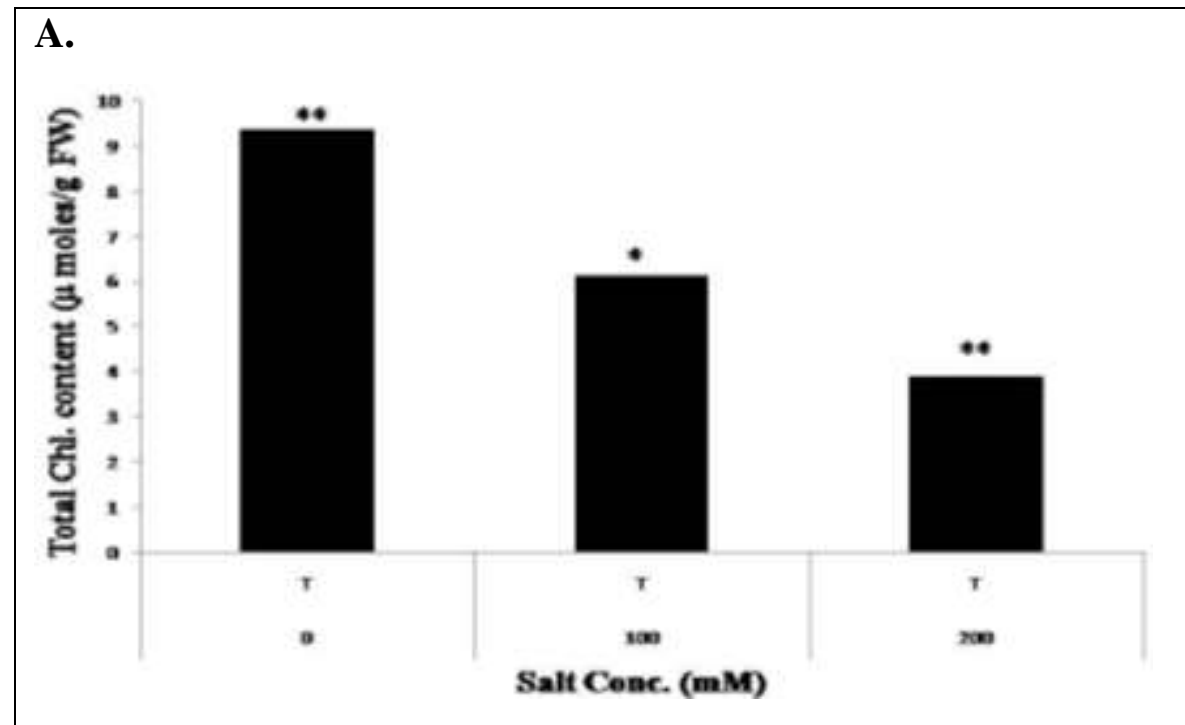

B.

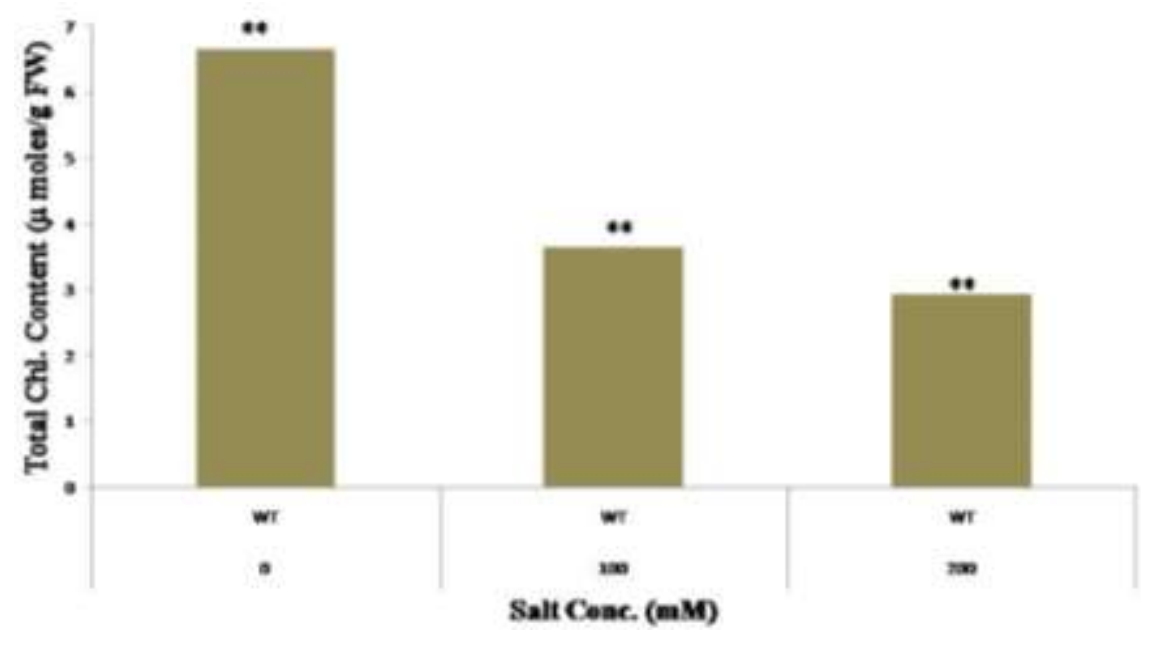

C.

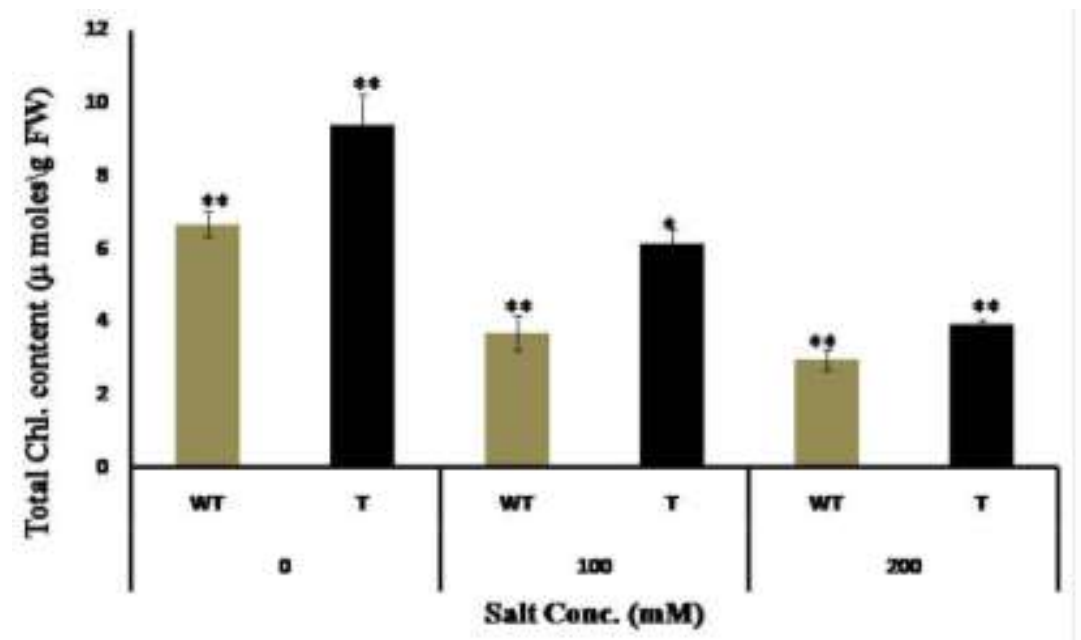

Fig. 12: Effect of Total Chlorophyll Content of transgenic Arabidopsis line (A.), Wild type (B.) and between Wild type and transgenic Arabidopsis (C.). 


\section{Discussion}

Plants need to maintain their water homeostasis for maintaining better growth and development and also for mitigating osmotic stress caused by abiotic sources such as salinity and drought. In order to maintain proper water homeostasis it is very essential for the plants to take up water via roots. Genetic evidences of the importance of aquaporin especially PIP in the water uptake by roots were known from the works of several workers, like (Martre et al., 2002; Siefritz et al., 2002). In these studies antisense constructs were used to knockdown PIP expression in tobacco and Arabidopsis and PIP2;2 genes were knocked out from Arabidopsis using T-DNA inserts. The knock down of PIP expression in Tobacco and Arabidopsis and knock out of PIP 2;2 genes in Arabidopsis resulted in a significant reduction in root hydraulic conductance. In various studies it was found that a rise in concentrations of salt has shown to inhibit root water uptake due to reduction in root hydraulic conductance in several plant species including Arabidopsis and maize (Azaizeh and Steudle, 1991; Peyrano et al., 1997; Carvajal, 1999; MartinezBallesta, 2003; Martinez-Ballesta, 2000; Boursiac et al., 2005) but a contradictory report also existed and it suggested that salinity stress does not hamper the increase or decrease of hydraulic resistance and in spite of stressed condition the plants seems to grown in a similar manner to that of unstressed plant (Boursiac et al., 2005). These studies motivated us in our quest of understanding the components of water transport via $H v \mathrm{PIP} 2 ; 4$ aquaporin gene. The present study was ventured to figure out the potential of $H v P I P 2 ; 4$ in conferring abiotic stress tolerance in Arabidopsis. Here we have overexpressed Barley aquaporin HvPIP2;4 in Arabidopsis and this was authenticated for salt tolerance. Inplanta transformation system was used to introduce $H v$ PIP $2 ; 4$ gene with a binary vector pCAMBIA 2301::CAMV35S:HvPIP2;4:Poly A.

For confirmation of the transgenic event the putative transgenic plants were analysed through molecular biology techniques. Genomic DNA analysis was done using nptII gene as marker. The PCR analysis detected the presence of the expected 540bp amplified product corresponding to nptII (Fig. 2) in transformed plants. So, for further physiological and biochemical analysis putative transformants were taken under consideration.

Transgenic Arabidopsis plant expressing HvPIP2;4 showed improved tolerance to salinity.

Physiological analysis was performed to determine the salt tolerance of 35S:HvPIP2;4 transgenic Arabidopsis line. Under unstressed conditions no significant difference of growth was found between wild type and transgenic Arabidopsis line. Overexpression of HvPIP 2;4 conferred salt tolerance to transgenic Arabidopsis line. The transgenic grew better than the wild type in 100 and $200 \mathrm{mM} \mathrm{NaCl}$ stressed condition. There was previous report that rapid water transportability was shown by PIP 2 protein (Boursaic et al., 2005, Munns and Passioura, 1984) and this phenomenon was also reported in Rice Plants OsPIP2-2 (Martre et al., 2002). The above data indicates that transgenic plants over expressing $H v P I P 2 ; 4$ displayed high tolerance to mild salt stress. This shows that $H v P I P 2 ; 4$ could possibly have intrinsic water trans- portability inplanta and play a important role in regulating water homeostasis.

The root length of the transgenic 35S: HvPIP2;4 Arabidopsis varieties was more than that of the wild type even in unstressed conditions.

Because Aqp gene mediate and regulate rapid transmembrane water flow during growth and development, $H v P I P 2 ; 4$ overexpressing plants may be more efficient in regulating water transport across membranes under stressed conditions. It is speculated that the physiological effects are beneficial for plants in maintaining the protein machinery that regulates nutrient uptake and distribution.

With the gradual increase in stress (100 and 200mM) there was a reduction in the root length both in the transgenic and wild varieties.

Salinity stress affects the vital photosynthetic system components including the chlorophyll content. In Transgenic HvPIP2;4 varieties Chlorophyll pigments were found to be more than that in wild type. With the gradual increase in stress $(100 \mathrm{mM} \& 200 \mathrm{mM} \mathrm{NaCl})$ there was a decrease in the amount of Chlorophyll content. Due to the presence of more chlorophyll pigment in $H v P I P 2 ; 4$ transgenic lines the transgenic plants showed better growth and development than wild types and they could mitigate stress easily. By measuring the biomass of Arabidopsis seedlings the increase in salinity tolerance was quantified. After harvest the salt stressed 35S:HvPIP2;4 expressing Arabidopsis line yielded significantly more fresh weight than the stressed wild type control. The relative water content is an indicator for water status in leaves, Our results indicated that $H v$ PIP 2;4 transformed Arabidopsis lines had higher relative water content than the wild type. These results suggested that $H v \mathrm{PIP} 2 ; 4$ expression enhanced the osmotic regulation capability of transgenes and had thus enhanced the salt stress tolerance in transgenic Arabidopsis this phenomenon has also been reported from OsPIP1-1 and OsPIP2-2 (Guo et al., 2006). A similar result was obtained when TaNIP gene was introduced in Arabidopsis and transgenic Arabidopsis showed enhanced salt tolerance.

In this study aquaporin is found to play a very important role in mitigating salt stress tolerance similar results were obtained from the works of (Gao et al., 2010, Guo et al 2006, Jhang et al 2007, Sade et al 2010, Ayadi et al 2011) 
This result suggested that the $H v P I P 2 ; 4$ gene play important role in regulating water homeostasis and that $H v P I P 2 ; 4$ gene could possibly have intrinsic water transportability in planta. The expression pattern showed $\mathrm{NaCl}$ dose dependency during stressed condition. Salt tolerance was enhanced costitutively in transgenic Arabidopsis and HvPIP2;4 played a constructive role in increasing plant salt tolerance. It may be very well presumed that overexpression of $H v P I P 2 ; 4$ in crop plant might benefit them by enhancing their salt tolerance capacity.

\section{References}

Agre P and Homer W (2000) Smith award lecture. Aquaporin water channels in kidney. J. Am. Soc. Nephrol. 11: 764777 .

Amodeo G, Dorr R, Vallejo A, Stuka M and Parisi M (1999) Radial and axial water transport in the sugar beet storage root. J. Exp. Bot. 50: 509-516. DOI: 10.1093/jxb/50.333.509

Arnon DI (1949) Copper enzymes in isolated chloroplasts: polyphenoloxidase in Beta vulgaris. Plant Physiol. 24: 1. DOI: $10.1104 /$ pp.24.1.1

Ayadi M, Cavez D, Miled N, Chaumont F, Masmoudi K (2011) Identification and characterization of two plasma membrane aquaporins in durum wheat (Triticum turgidum L. subsp. durum) and their role in abiotic stress tolerance. Plant Physiol Biochem. 49: 1029-1039. DOI: 10.1016/j.plaphy.2011.06.002

Azaizeh H and Steudle E (1991) Effects of salinity on water transport of excised maize (Zea mays L.) roots. Plant Physiol. 97: 1136-1145. DOI: 10.1104/pp.97.3.1136

Baiges I, Schaffner AR, Affenzeller M J, Mas A (2002) Plant Aquaporins. Physiologia Plant 115(2): 175-182. DOI: 10.1034/j.1399-3054.2002.1150201.x

Bilgin DD, DeLucia EH, Clough JS (2009) A robust plant RNA isolation method suitable for AffymetrixGeneChip analysis and quantitative real-time RT-PCR. Nature Protocols 4(3): 333-340. DOI: $10.1038 /$ nprot.2008.249

Boursiac Y, Chen S, Luu DT, Sorieul M, van den Dries N, Maurel C (2005) Early effects of salinity on water transport in Arabidopsis roots. Molecular and cellular features of aquaporin expression. Plant Physiol. 139: 790-805. DOI: $10.1104 /$ pp. 105.065029

Carvajal MM, Martinez V, Alcaraz CF (1999) Physiological function of water channels as affected by salinity in roots of paprika pepper. Physiol. Plant 105: 95-101. DOI: 10.1034/j.1399-3054.1999.105115.x

Chaumont F, Barrieu F, Wojcik E, Chrispeels MJ, Jung R (2011) Aquaporins constitute a large and highly divergent protein family in maize. Plant Physiol. 125: 1206-1215. DOI: 10.1104/pp.125.3.1206

Clough SJ, and Bent AF (1998) Floral Dip:a simplified method for Agrobacterium mediated transformation of Arabidopsis thaliana. Plant Journal 16 (6): 735-743. DOI: 10.1046/j.1365-313x.1998.00343.x
Gao ZX, He XL, Zhao BC, Zhou CJ, Liang YZ, Ge RC, Shen Y, Huang $Z$ (2010) Overexpressing a putative aquaporin gene from wheat, TaNIP, enhances salt tolerance in transgenic Arabidopsis. Plant Cell Physiol. 51: 767-775. DOI: 10.1093/pcp/pcq036

Guo L, Wang ZY, Lin H, Cui WE, Chen J, Liu M, Chen ZL, Qu $\mathrm{LJ}$ and $\mathrm{Gu} \mathrm{H}$ (2006) Expression and functional analysis of the rice plasma-membrane intrinsic protein gene family. Cell Research 16: 277-286. DOI: 10.1038/sj.cr.7310035

Heymann JB and Engel A (1999) Aquaporins: phylogeny, structure, and physiology of water channels. News. Physiol. Sci. 14: 187-193.

Hollenbach B, and Dietz K (1995) Molecular cloning of emip, a member of the major intrinsic protein (MIP) gene family, preferen-tially expressed in epidermal cells of barley leaves. Bot. Acta 108: 425-431. DOI: 10.1111/j.14388677.1995.tb00516.x

Jang JY, Rhee JY, Kim DG, Chung GC, Lee JH and Kang H (2007) Ectopic expression of a foreign aquaporin disrupts the natural expression patterns of endogenous aquaporin genes and alters plant responses to different stress conditions. Plant Cell Physiol. 48: 1331-1339. DOI: 10.1093/pcp/pcm101

Johanson U, Karlsson M, Johansson I, Gustavsson S, Sjo“vall S, Fraysse L, Weig AR and Kjellbom P (2001) The complete set of genes encoding major intrinsic proteins in Arabidopsis provides a framework for a new nomenclature for major intrinsic proteins in plants. Plant Physiol. 126: 1358-1369. DOI: 10.1104/pp.126.4.1358

Katsuhara M and Shibasaka M (2007) Barley root hydraulic conduct- ivity and aquaporins expression in relation to salt tolerance. Soil Sci. Plant Nutr. 53: 466-470. DOI: 10.1111/j.1747-0765.2007.00154.x

Katsuhara M, Hanba YT, Shiratake K, Maeshima M (2008) Expanding roles of plant aquaporins in plasma membranes and cell organelles. Funct. Plant Biol. 35: 1-14. DOI: 10.1071/FP07130

Katsuhara, M, Akiyama Y, Koshio K, Shibasaka M and Kasamo K (2002) Functional analysis of water channels in barley roots. Plant Cell Physiol. 43: 885-893. DOI: 10.1093/pcp/pcf102

Kronzucker, HJ and Britto DT (2011) Sodium transport in plants: a critical review. New Phytol. 189: 54-58. DOI: 10.1111/j.1469-8137.2010.03540.x

Mahajan S and Tuteja N (2005) Cold, salinity and drought stresses: an overview. Arch Biochem. Biophys. 444: 139-158.DOI: 10.1016/j.abb.2005.10.018

Martinez-Ballesta MC (2000) Regulation of water channel activity in whole roots and in proto- plasts from roots of melon plants grown under saline conditions. Aust. J. Plant Physiol. 27: 685-691.

Martinez-Ballesta MC, Aparicio F, Pallas V, Martinez V and Carvajal M (2003) Influence of saline stress on root hydraulic con-ductance and PIP expression in Arabidopsis. J. Plant Physiol. 160: 687-697. 
Martre P, Morillon R, Barrieu F, North GB, Nobel PS and Chrispeels MJ (2002) Plasma membrane aquaporins play a significant role during recovery from water deficit. Plant Physiol. 130: 2101-211. DOI: 10.1104/pp.009019

Maurel C, Javot H, Lauvergeat V, Gerbeau P, Tournaire C, Santoni V and Heyes J (2002) Molecular physiology of Aquaporins in plants. International Review of Cytology A Survey of Cell Biology 215: 105-148. DOI: 10.1016/s0074-7696(02)15007-8

Munns R and Passioura JB (1984) Hydraulic resistance of plants. III. Effects of $\mathrm{NaCl}$ in barley and lupin. Aust. J. Plant Physiol 11: 351-359. DOI: 10.1071/PP9840351

Nagel R, Elliot A, Masel A, Birch RG and Manners JM (1990) Electroporation of binary $\mathrm{Ti}$ plasmid vector into Agrobacterium tumefaciens and Agrobacterium rhizogenesis. FEMS Microbiol. Lett. 67: 325-328. DOI: 10.1111/j.1574-6968.1990.tb04041.x

Obroucheva NV and Sin'kevich IA (2010) Aquaporins and cell growth. Russ J Plant Physiol. 57: 153-165. DOI: 10.1134/S1021443710020019

Park W, Scheffler BE, Bauer PJ and Campbell BT (2010) Identification of the family of aquaporin genes and their expression in upland cotton (Gossypium hirsutum L.). BMC Plant Biol. 10: 142. DOI: 10.1186/1471-2229-10142

Peyrano G, Taleisnik E, Quiroga M, de Forchetti SM and Tigier H (1997) Salinity effects on hydraulic conductance, lignin content and peroxidase activity in tomato roots. Plant Physiol. Biochem. 35: 387-393.

Preston GM, Carroll TP, Guggino WB and Agre P (1992) Appearance of water channels in Xenopus oocytes expressing red cell CHIP28 protein. Science 256: 385-387. DOI: $10.1126 /$ science. 256.5055 .385

Quigley F, Rosenberg JM, Shahar-Hill Y and Bonhert HJ (2002) From genome to function: The Arabidopsis aquaporins. Genome Biol. 3: 1-17.

Reuscher S, Akiyama M, Mori C, Aoki K, Shibata D and Shirataka K (2013) Genome-wide identification and expression analysis of aquaporins in tomato. PLoS One 8(e): 79052. DOI: 10.1371/journal.pone.0079052

Rogers SO and Bendich AJ (1988) In: Gelvin SB, Schilperoort RA (eds). Plant molecular biology manual, A (6): 1-10.

Sade N, Gebretsadik M, Seligmann R, Schwartz A, Wallach R, Moshelion M (2010) The role of tobacco Aquaporin1 in improving water use efficiency, hydraulic conductivity, and yield production under salt stress. Plant Physiol, 152: 245-254. DOI: $10.1104 / p p .109 .145854$

Sakurai J, Ishiawa F, Yamaguchi T, Uemura M and Meshima M (2005) Identification of 33 rice aquaporin genes and analysis of their expression and function. Plant Cell Physiol. 46: 1568-1577. DOI: 10.1093/pcp/pci172

Sambrook J and Green MR (2001) Molecular Cloning: A Laboratory Manual.4th edition. Cold Spring Harbor Laboratory Press.

Schneider CA, Rasband WS and Eliceiri KW (2012) NIH Image to ImageJ: 25 years of image analysis. Nature methods 9(7): 671-675. DOI: 10.1038/nmeth.2089

Siefritz F, Tyree MT, Lovisolo C, Schubert A and Kaldenhoff R (2002) PIP1 plasma membrane aquaporins in tobacco: from cellular effects to function in plants. Plant Cell 14(4): 869-876. DOI: $10.1105 /$ tpc.000901

Smart RE and Bingham GE (1974) Rapid estimates of relative water content. Plant Physiology 53(2): 258-260. DOI: 10.1104/pp.53.2.258

Taiz L and Zeiger E (2006) Plant Physiology Sinauer.

Töpfer R, Matzeit V, Gronenborn B, Schell J and Steinbiss H (1987) A set of plant expression vectors for transcriptional and translational fusions. Nucleic Acids Res. 15(14): 5890. DOI: $10.1093 /$ nar/15.14.5890

Wei W, Alexandersson E, Golldack D, Miller AJ, Kjellbom PO and Fricke W (2007) $H \nu$ PIP1;6, a barley (Hordeum vulgare L.) plasma membrane water channel particularly expressed in growing com- pared with non-growing leaf tissues. Plant Cell Physiol. 48: 1132-1147. DOI: $10.1093 / \mathrm{pcp} / \mathrm{pcm} 083$ 